\title{
SAFETY TEST ON LOOSE PARTICLES FROM IRRADIATED COMPACT 4-4-2
}

\author{
J.D. Hunn, R.N. Morris, C.A. Baldwin, and F.C. Montgomery
}

\section{Introduction}

Post-irradiation examination (PIE) is being carried out on coated particle fuel compacts from the first Advanced Gas Reactor (AGR) Fuel Development and Qualification irradiation experiment (AGR-1). The Oak Ridge National Laboratory (ORNL) Core Conduction Cooldown Test Facility (CCCTF) has been used to evaluate the effect of elevated temperature on the fuel microstructure and fission product retention by heating compacts to maximum temperatures of 1600,1700 , or $1800^{\circ} \mathrm{C}$ for typically 300 hours, where $1600^{\circ} \mathrm{C}$ is the expected maximum temperature during a high-temperature gas-cooled reactor (HTGR) depressurization conduction cooldown event, while 1700 and $1800^{\circ} \mathrm{C}$ explore the performance margin. After completing eleven standard safety tests, a different type of experiment was conducted [INL/PLN4650], where, rather than heating an entire as-irradiated fuel compact, loose particles were tested after deconsolidation of a compact and separation of the particles from the compact matrix.

Compact 4-4-2 was an AGR-1 Variant 3 fuel compact [ORNL/TM-2012/295] that was irradiated at the Idaho National Laboratory (INL) Advanced Test Reactor (ATR) to an average calculated burnup of $16.7 \%$ fissions per initial metal atom (FIMA) and an average calculated fast fluence of $3.59 \cdot 10^{25} \mathrm{n} / \mathrm{m}^{2}$, while at a calculated time-averaged and volume-averaged temperature of approximately $1024^{\circ} \mathrm{C}$. AGR-1 Compact 4-4-2 was previously subjected to PIE in the as-irradiated condition [INL/PLN-3845], and results were reported in the AGR-1 Compact 4-4-2 PIE Report [ORNL/TM-2013/236]. After deconsolidation and pre-burn leaching of the as-irradiated compact, 90 randomly-selected particles were individually gamma scanned for four hours each with the ORNL Irradiated Microsphere Gamma Analyzer (IMGA). These particles were not subjected to burn-leach after the IMGA analysis, but were retained as archives with all tristructural isotropic (TRISO) coating layers still intact. Seventy-five of these archived particles were used in the loose particle heating test.

The loose particles were loaded into ring-shaped graphite trays (Figure 1). Each tray had 15 singleparticle sample wells that were labeled and indexed to maintain individual particle identity. Five trays were held in a stack using a threaded graphite rod and graphite nut, resulting in a final assembled dimension similar to a typical AGR-1 compact. The tray assembly was then placed in a standard CCCTF graphite fuel holder.
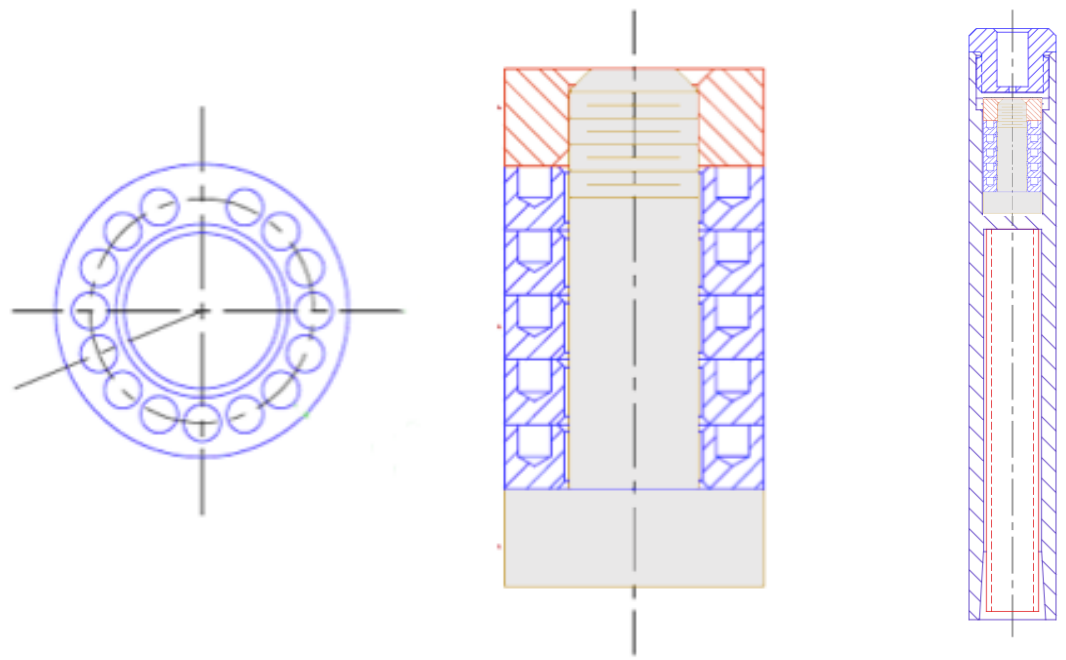

Figure 1. CCCTF fuel holder assembly for the loose particle test.

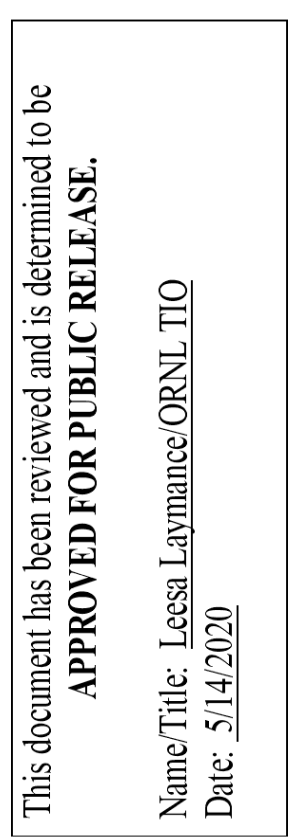


The loose particles were heated in pure helium in the CCCTF to a maximum temperature of $1800^{\circ} \mathrm{C}$. Particles were heated for an extended period (650 hours) to maximize the opportunity for fission product release through intact $\mathrm{SiC}$ (especially silver). During the safety test, as the particles were heated, condensable fission products (metallic elements) were collected by the CCCTF in-furnace cold finger and gaseous fission products were collected from the helium sweep gas as it passed through liquid nitrogencooled cold traps. Deposition cups attached to the in-furnace cold finger were periodically removed and analyzed by gamma spectrometry, and the sweep gas traps were constantly monitored for gamma activity from ${ }^{85} \mathrm{Kr}$ throughout the run.

After completion of the safety test, additional analysis was performed on the deposition cups and other CCCTF furnace internals (graphite tray assembly, graphite fuel holder, tantalum furnace liner, and tantalum gas inlet line) to measure the activity from the radioactive fission products that were transferred from the particles to these various furnace components. The average deposition cup collection efficiency was determined for each fission product by measuring the total release from the particles (summing the inventories measured on the graphite tray assembly, graphite holder, tantalum furnace internals, and deposition cups) and calculating the fraction of the total that went to the cups. The average collection efficiency was then used to adjust the time-dependent deposition cup data to estimate the time-dependent fission product release from the particles.

\section{Safety Test Results}

Figure 2 shows the cumulative releases of krypton and cesium. The plotted inventory releases are in terms of the average particle inventory [INL/ECAR-958, Rev. 2]. Significant krypton release is indicative of failure of all three gas-tight outer TRISO coatings. The ${ }^{85} \mathrm{Kr}$ release shown in Figure 2 indicates that there were three particles with TRISO failure during the initial heat-up to $1800^{\circ} \mathrm{C}$, and two more particles failed while at $1800^{\circ} \mathrm{C}$. Cesium release is indicative of failure of the $\mathrm{SiC}$ layer (intact pyrocarbon will retain krypton, but not cesium). Cesium release occurred concurrent with the initial TRISO failure and with the TRISO failure at $\sim 150$ hours into the test. Figure 3 shows that the rate of cesium collection on the deposition cups was highest on the deposition cups that were in the furnace at the time of the krypton release, and had dropped back to a negligible level by the end of the next 24-hour cup exchange period. The final increase in cesium release at about 450 hours into the test appeared to precede the final TRISO failure, probably indicating that the $\mathrm{SiC}$ failed prior to both pyrocarbon layers.

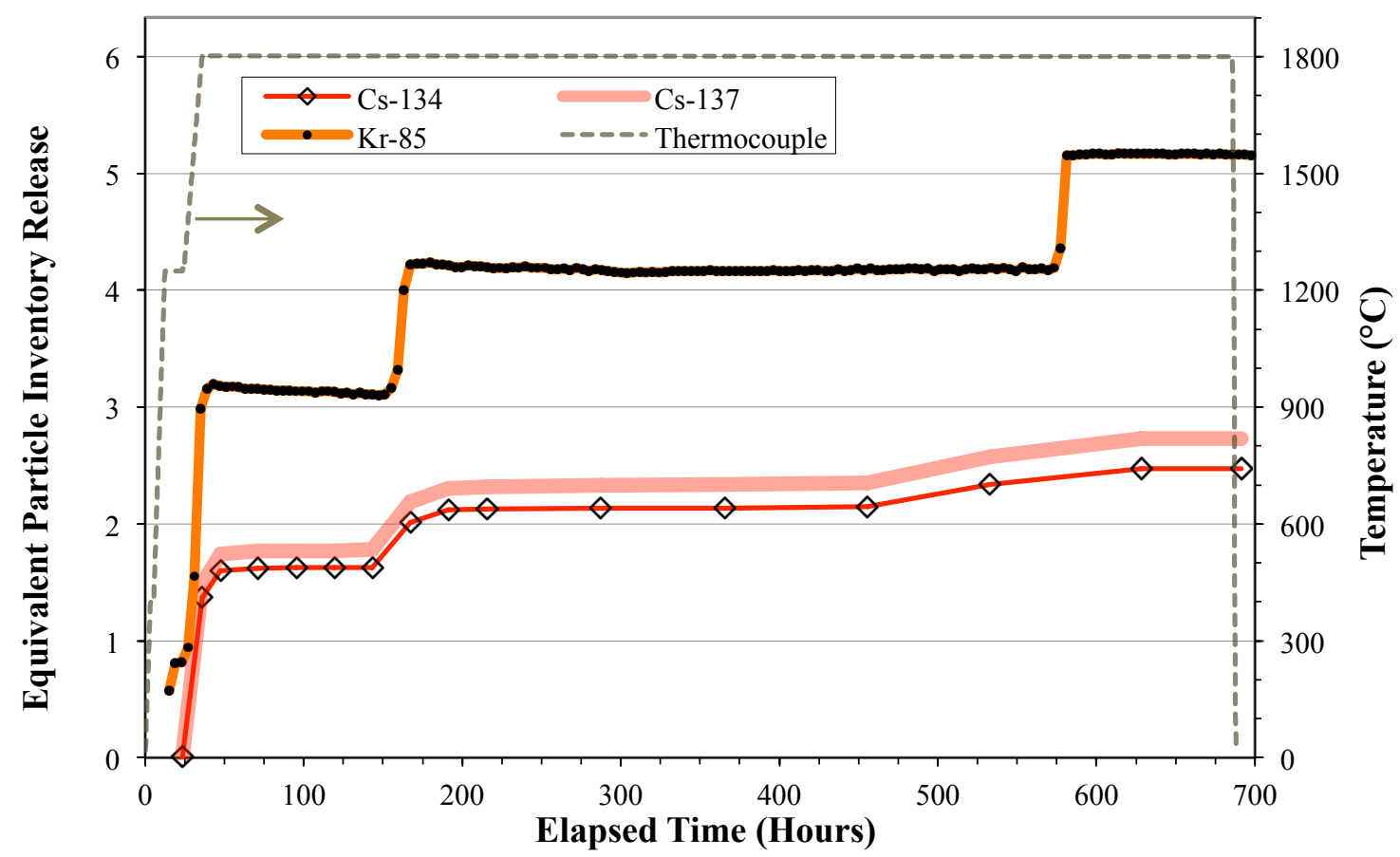

Figure 2. Cumulative release of cesium and krypton from Compact 4-4-2 loose particles at $1800^{\circ} \mathrm{C}$. 


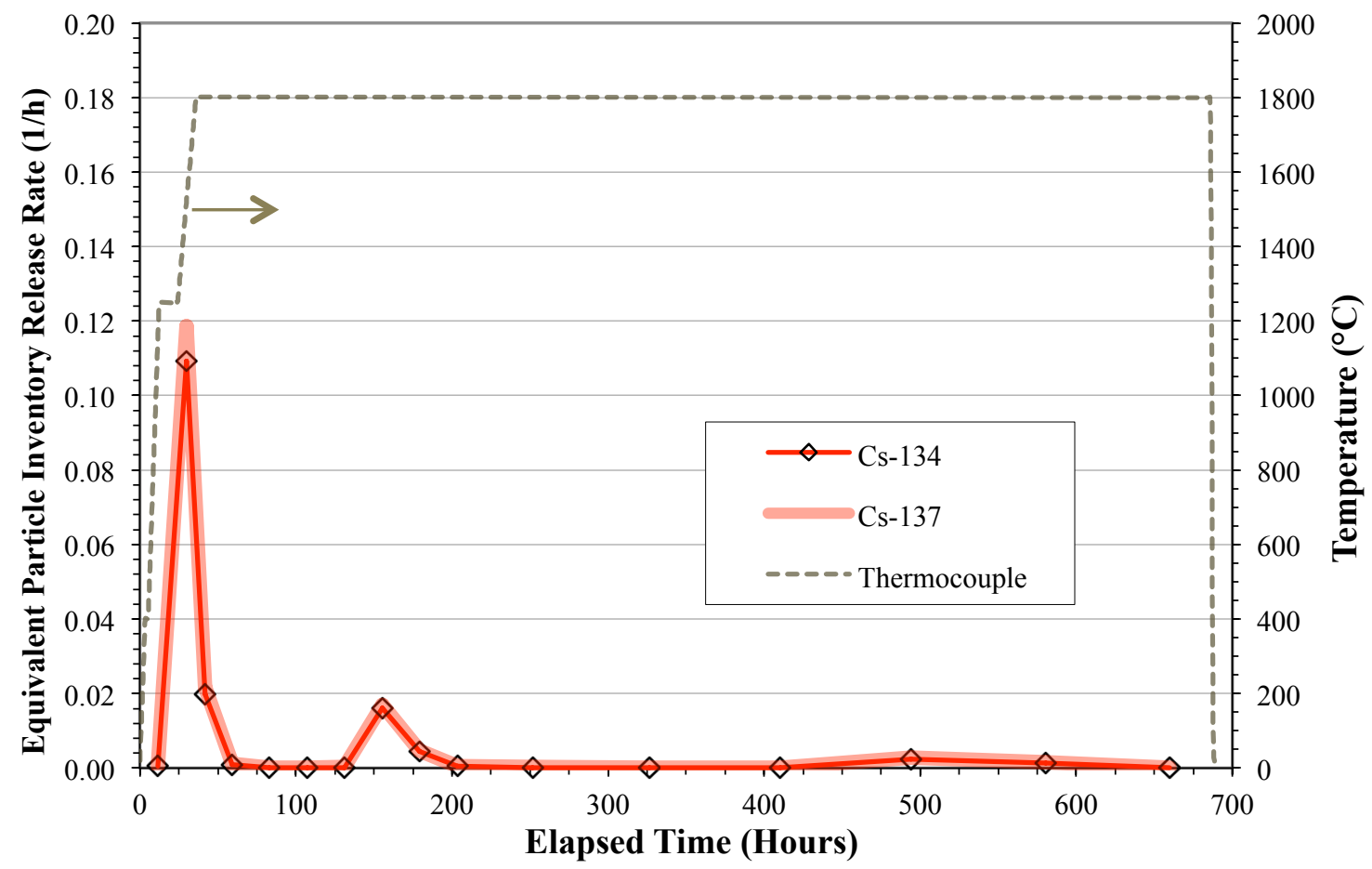

Figure 3. Average rate of cesium release during each deposition cup collection interval.

Release of some of the other measured radioisotopes is shown in Figure 4. Europium and strontium were gradually released throughout the test. Similar behavior has been observed in all the CCCTF tests and is believed to be a result of slow migration of these elements through the outer pyrocarbon (OPyC) and surrounding graphite, and reaction with the tantalum components. Table 1 lists the fraction of the total furnace test releases detected on various internal CCCTF furnace components at the end of the safety test and most of the europium appeared to be captured by the tantalum.

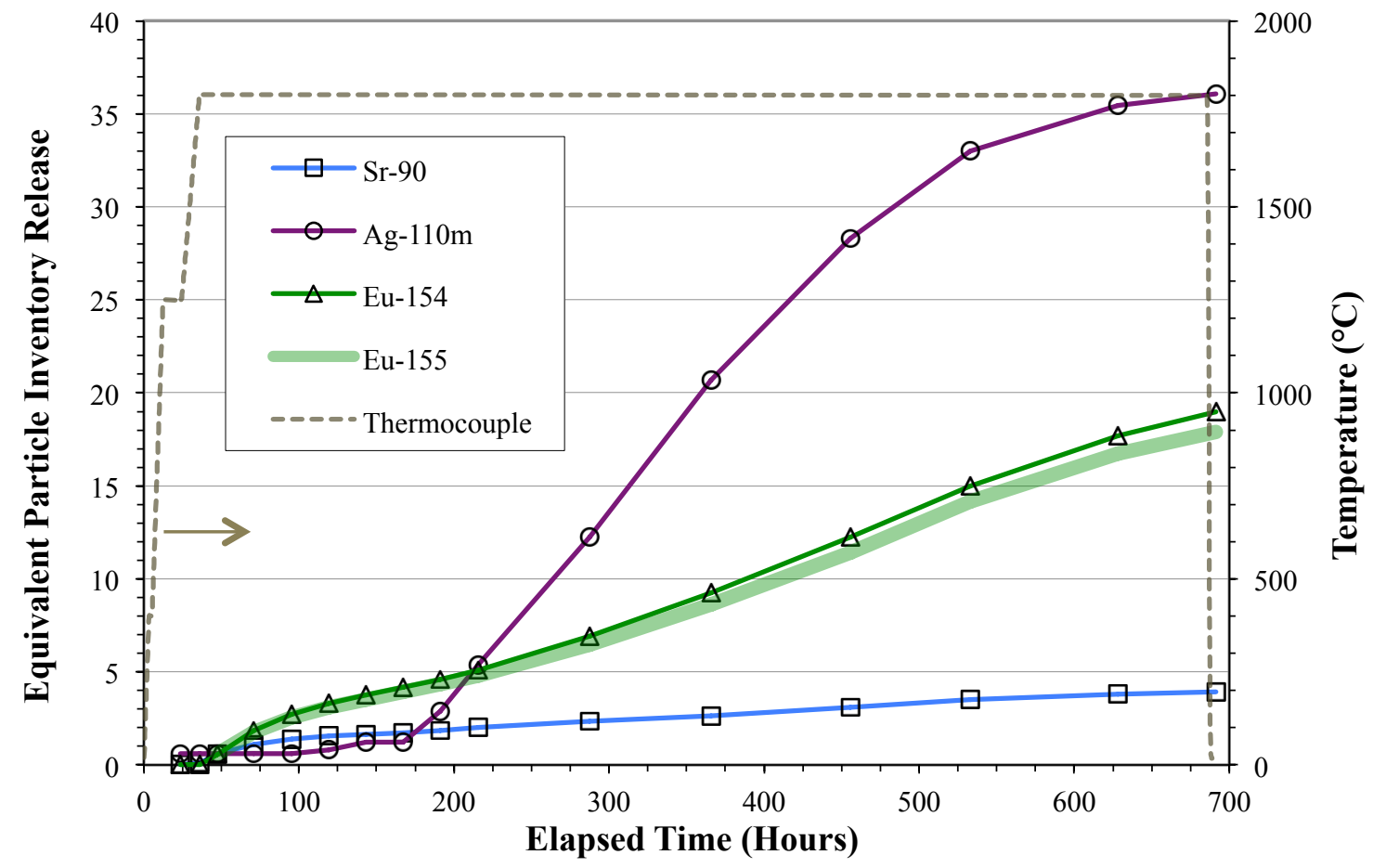

Figure 4. Cumulative release of silver, europium, and strontium from Compact 4-4-2 loose particles at $1800^{\circ} \mathrm{C}$. 
Table 1. Distribution of radioactive isotopes detected in the CCCTF furnace internals after the Compact 4-4-2 loose particle furnace test

\begin{tabular}{|c||c|c|c|c|c|}
\hline Component & ${ }^{\mathbf{9 0}} \mathbf{S r}$ & ${ }^{134} \mathbf{C s}$ & ${ }^{{ }^{110 m}} \mathbf{A g}$ & ${ }^{154} \mathbf{E u}$ & ${ }^{155} \mathbf{E u}$ \\
\hline \hline Deposition cups & $44.7 \%$ & $51.1 \%$ & $60.5 \%$ & $10.0 \%$ & $8.8 \%$ \\
\hline Tantalum parts & $52.5 \%$ & $48.9 \%$ & $39.5 \%$ & $85.8 \%$ & $87.0 \%$ \\
\hline Graphite holder & $2.8 \%$ & $<0.1 \%$ & $<0.1 \%$ & $4.0 \%$ & $4.2 \%$ \\
\hline Graphite trays & $<0.1 \%$ & $<0.1 \%$ & $<0.1 \%$ & $0.3 \%$ & $<0.1 \%$ \\
\hline
\end{tabular}

Silver release and distribution within the furnace was anomalous to typical CCCTF behavior. Silver is usually released from the compact matrix and OPyC during the initial heatup of a compact with relatively little additional release from the compact through the remainder of the safety test. Two exceptions to this behavior have been when test temperature was not held constant [ORNL/LTR-2014/485], which is not relevant here, and during the test of Compact 4-4-1 [ORNL/LTR-2013/291], which released the typical initial burst of silver during heatup followed by a secondary increase in silver release after about 150 hours at $1800^{\circ} \mathrm{C}$ (Figure 5). It is speculated that this secondary silver release may be related to the finergrained SiC microstructure unique to this AGR-1 Variant 3 fuel type. Compact 4-3-2 (also Variant 3) was safety tested in the INL FACS furnace and showed a similar behavior. The Compact 4-4-2 loose particles did not release much silver during initial heatup (Figure 4); this is probably due to the fact that there was no compact matrix in this safety test and any silver in the OPyC would have been removed by the deconsolidation leach. The onset of significant silver accumulation around 150-200 hours into the test is reminiscent of the Variant 3 compacts safety tested at $1800^{\circ} \mathrm{C}$. Figure 5 shows that additional silver was released from Compact 4-4-1 at essentially a constant rate for the last 100 hours at $1800^{\circ} \mathrm{C}$ (from roughly 230 to 330 hours into the test). Figure 4 shows a similar constant silver release from the Compact 4-4-2 loose particles over the same time interval, followed by an eventual tapering off in the release rate; this tapering off was a result of depletion of the silver inventory in the 75-particle test sample.

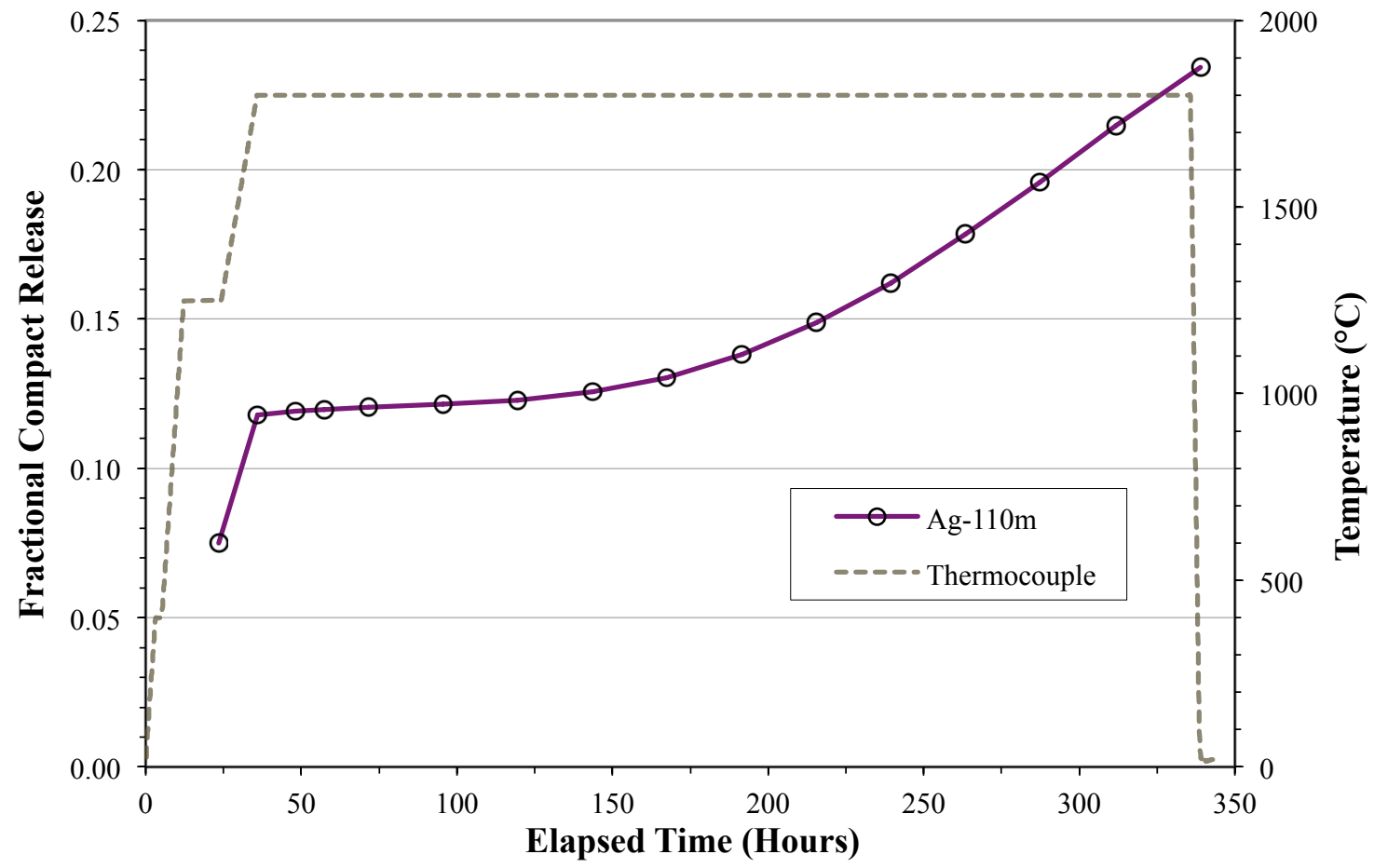

Figure 5. Time-dependent cumulative release of silver from $1800^{\circ} \mathrm{C}$ safety test of Compact 4-4-1. 
An unusually large fraction $(60.5 \%)$ of the total detected ${ }^{110 \mathrm{~m}} \mathrm{Ag}$ (Table 1) was located at the top of the furnace on the tantalum gas inlet line (above the deposition cup); other $1800^{\circ} \mathrm{C} \mathrm{CCCTF}$ safety tests have exhibited $>99 \%$ average collection efficiency for silver. The mechanism by which the silver bypassed the deposition cups to be deposited on the gas line is being investigated. It is possible that the deposition cup temperature was not as low as it should have been due to some unknown furnace problem. Cesium and europium were also detected on the gas line at the top of the furnace; these elements also exhibited lower than expected collection efficiencies. The Compact 4-2-2 safety test [ORNL/LTR-2014/485] followed the loose particle test and showed a similar cup collection problem. It is unlikely that fission products collected at the top of the furnace are transported back down to the deposition cup, which is closer to the heated zone and at a higher temperature. Therefore, this anomalous reduced collection efficiency should not impact the general conclusions drawn from these two furnace tests, but may impact the quantitative analysis of the total release due to large uncertainty in the measurement of fission products that may have collected at the top of the furnace can. Refinement of the quantitative furnace test releases from the Compact 4-4-2 loose particles is available from the IMGA measurement of various radioisotopic inventories before and after the test; this data will be presented in a future summary report of the postsafety test PIE.

\section{Conclusion}

An $1800^{\circ} \mathrm{C}$ furnace test of loose particles deconsolidated from irradiated AGR-1 Compact 4-4-2 was successfully conducted to investigate individual fuel particle performance and release of fission products through intact $\mathrm{SiC}$ at $1800^{\circ} \mathrm{C}$. Five particles experienced full-TRISO failure (Figure 2), releasing essentially all of their krypton inventory. This type of failure has not been observed in any other AGR-1 safety test conducted in the CCCTF and is thought to be due to a reduction in TRISO layer performance as a result of the removal of the surrounding matrix and possible impact of deconsolidation and particle handling on the TRISO particle integrity. Multiple-particle SiC failure has been observed in AGR-1 compacts heated to $1800^{\circ} \mathrm{C}$, and this failure was accompanied by IPyC cracking [ORNL/TM-2014/484]. In these particles with failed $\mathrm{SiC}$, the OPyC layer presented the last line of defense against krypton release. In the Compact 4-4-2 loose particle test, the OPyC layer did not have additional structural support from the matrix and may have been compromised by the deconsolidation. At the end of the loose particle safety test, all five particles that had experienced TRISO failure were recovered intact and microstructural analysis of these particles will be presented in a future summary report of the post-safety test PIE. Analysis of cesium release indicated that no additional particles with failed $\mathrm{SiC}$ were present in the experimental sample beyond the five particles that also had failed pyrocarbon layers.

Silver and europium release from the loose particles heated at $1800^{\circ} \mathrm{C}$ was greater than can be accounted for by release from the five particles with failed TRISO (Figure 4). Deconsolidation leach-burn-leach analysis of the Compact 4-4-2 particles prior to the furnace test indicated that very little silver or europium resided outside of intact SiC layers at the beginning of the test [ORNL/TM-2013/236]. Therefore most of the silver and europium detected in the CCCTF can be presumed to have come through intact SiC layers. Post-safety test analysis using IMGA to quantify the fission product release from individual fuel particles will be presented in a future summary report.

\section{Acknowledgments}

This work was supported by the U.S. Department of Energy, Office of Nuclear Energy, under the Very High Temperature Reactor Technology Development Office Advanced Gas Reactor Fuel Development and Qualification Program. Hot cell activities were supported by the staff of the ORNL Irradiated Fuels Examination Laboratory (IFEL), and analysis of deposition cups and internal furnace component leach solutions was provided by the ORNL Nuclear Analytical Chemistry \& Isotopics Lab. 